\title{
Non-union ulnar fracture as a result of a remote injury
}

\author{
William Calawerts, ${ }^{1}$ Cleveland Piggott, ${ }^{1}$ Morteza Khodaee (1) ${ }^{2}$
}

${ }^{1}$ Department of Family Medicine, University of Colorado Denver School of Medicine, Denver, Colorado, USA

${ }^{2}$ Department of Family Medicine and Orthopedics, University of Colorado Denver School of Medicine, Denver, Colorado, USA

\section{Correspondence to} Professor Morteza Khodaee; morteza.khodaee@cuanschutz. edu

Accepted 17 March 2021

\section{DESCRIPTION}

A 45 -year-old man presented with a 2-year history of an enlarging left forearm mass. He has noted enlargement of his left forearm with associated pain with movement. The pain is worst with flexion on the lateral aspect of his forearm. The pain does not overtly limit his activities of daily living and improves with non-steroidal anti-inflammatory drugs. He denies numbness, tingling, weakness or unexpected weight loss. Patient recalled suffering an injury to his left forearm during a soccer game in Ghana at the age of 15 years. He was seen by a nurse who placed his forearm in a cast. No radiography images were obtained, and he had no further follow-up. He has never had issues with his forearm until the last few years. On physical examination, the patient has a notable deformity of the left forearm (figure 1). There was a palpable mass in the midulnar shaft without tenderness, erythema or skin break. His elbow and wrist range of motions were preserved with mild pain with supination, pronation and elbow flexion. He had normal strength and was neurovascularly intact. Plain radiography demonstrated a chronic and hypertrophic non-union ulnar diaphysis fracture with mild deformity of the radial diaphysis related to the healed fracture (figure 2). There was also moderate to severe osteoarthrosis of the elbow.

Paediatric and adolescent forearm diaphyseal fractures present a treatment challenge. ${ }^{1-3}$ Historically, both non-surgical and surgical treatments have been performed. ${ }^{13-5}$ The mainstay of the management is close clinical and radiographic follow-ups. Non-unions may occur in 2\%-10\% of all forearm fractures and can lead to dysfunction of the upper limb and hand. ${ }^{14}$ Compared with children,

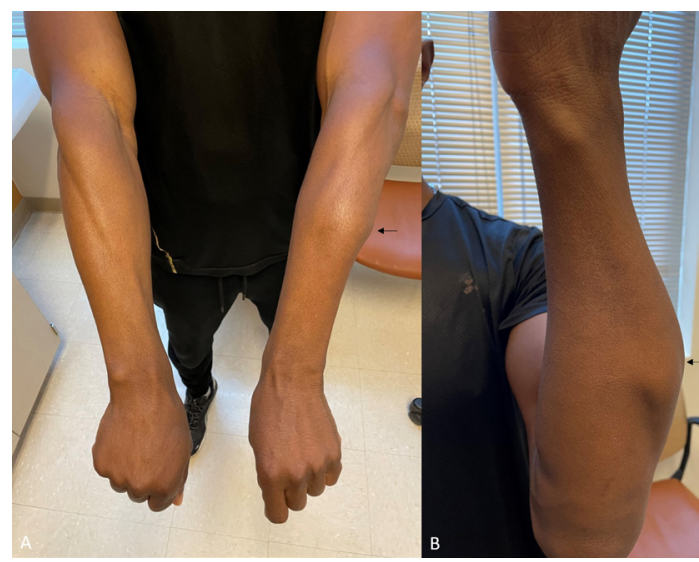

Figure 1 Left midforearm deformity (arrows) at the ulnar aspect ( $A$ and $B$ ).

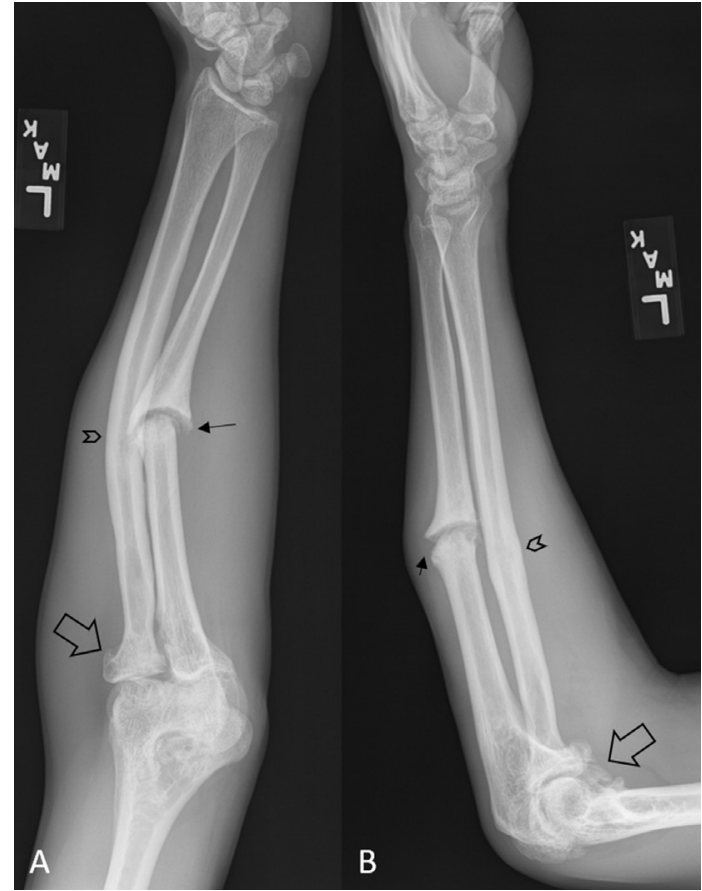

Figure 2 Plain anterior-posterior (A) and lateral (B) radiographs of left forearm demonstrating chronic, hypertrophic non-union (pseudarthrosis) ulnar diaphysis fracture (arrows) with deformity of radial diaphysis consistent with a healed remote fracture (arrowheads). Moderate to severe elbow osteoarthrosis is also present (open arrows).

adolescents and adults are more likely to develop malunions and non-unions. ${ }^{36}$ Other potential risk factors for non-unions are open fractures, inadequate stability (eg, suboptimal immobilisation or surgical fixations), associated infections and insufficient metabolic (eg, callus formation) response (eg, smoking and diabetes). ${ }^{16}$ Non-union can be further categorised into hypertrophic and atrophic types. Hypertrophic non-union is characterised by

\section{Learning points}

- Forearm injuries require a comprehensive clinical evaluation that should include radiographic images in most cases, particularly with any deformity or loss of function.

- Regardless of the treatment strategy, forearm fractures need close clinical and radiographic follow-ups.

- Patients with radius or ulna non-unions should be referred to orthopaedic surgery. 
adequate callus formation without adequate stability. ${ }^{6}$ However, atrophic non-unions occur due to the lack of callus formation usually due to inadequate vascularity or metabolic aetiologies. ${ }^{6}$ Despite non-union, in some cases, patients may maintain reasonable function for years. ${ }^{167}$ The primary goal of treatment is to restore the functional anatomy between the radius and ulna through maintaining their respective lengths and thus obtain optimum function. ${ }^{1}$ Prolonged radial and ulnar non-union may cause significant disability due to osteoarthrosis and decreased range of motion of adjacent joints. ${ }^{2}$ Patients with malunions and non-unions should be referred to an orthopaedic surgeon for further evaluation and treatment. ${ }^{1246}$ Our consultant orthopaedic surgeon recommended an elective ulnar open reduction and internal fixation with bone graft. ${ }^{68}$

Contributors All authors participated in patient's care, literature review, and manuscript preparation and approval.

Funding The authors have not declared a specific grant for this research from any funding agency in the public, commercial or not-for-profit sectors.

Competing interests None declared.

Patient consent for publication Obtained.
Provenance and peer review Not commissioned; externally peer reviewed.

\section{ORCID iD}

Morteza Khodaee http://orcid.org/0000-0003-3549-5333

\section{REFERENCES}

1 Boussakri H, Elibrahimi A, Bachiri M, et al. Nonunion of fractures of the ulna and radius Diaphyses: clinical and radiological results of surgical treatment. Malays Orthop J 2016;10:27-34

2 Nithyananth M, Cherian VM, Amritanand R, et al. Childhood nonunion of ulna presenting with wrist deformity in an adult: a case report. Arch Orthop Trauma Surg 2008;128:717-22.

3 Truntzer J, Vopat ML, Kane PM, et al. Forearm diaphyseal fractures in the adolescent population: treatment and management. Eur J Orthop Surg Traumatol 2015;25:201-9.

4 Kloen P, Wiggers JK, Buijze GA. Treatment of diaphyseal non-unions of the ulna and radius. Arch Orthop Trauma Surg 2010;130:1439-45.

5 Passiatore M, De Vitis R, Perna A, et al. Extraphyseal distal radius fracture in children: is the cast always needed? A retrospective analysis comparing Epibloc system and $\mathrm{K}$-wire pinning. Eur J Orthop Surg Traumatol 2020:30:1243-50.

6 Srinivasan RC, Hutson RL, Richard MJ. Forearm nonunion: characterization and management. J Hand Surg Am 2020;45:1055-64.

7 Richard MJ, Ruch DS. Aldridge JM 3rd. Malunions and nonunions of the forearm. Hand Clin 2007;23:235-43.

8 De Vitis R, Passiatore M, Cilli V, et al. Intramedullary nailing for treatment of forearm non-union: Is it useful? - A case series. J Orthop 2020;20:97-104.

Copyright 2021 BMJ Publishing Group. All rights reserved. For permission to reuse any of this content visit

https://www.bmj.com/company/products-services/rights-and-licensing/permissions/

BMJ Case Report Fellows may re-use this article for personal use and teaching without any further permission.

Become a Fellow of BMJ Case Reports today and you can:

- Submit as many cases as you like

Enjoy fast sympathetic peer review and rapid publication of accepted articles

- Access all the published articles

Re-use any of the published material for personal use and teaching without further permission

Customer Service

If you have any further queries about your subscription, please contact our customer services team on +44 (0) 2071111105 or via email at support@bmj.com.

Visit casereports.bmj.com for more articles like this and to become a Fellow 